\title{
Exploring the diversification benefits of US international equity closed-end funds
}

\author{
Jonathan Fletcher ${ }^{1}$ (1)
}

Accepted: 23 March 2021 / Published online: 29 June 2021

(c) The Author(s) 2021

\begin{abstract}
I use the simulation approach of Jobson and Korkie (J Portfolio Manag 7:70-74, 1981), combined with Michaud optimization (Michaud and Michaud, Efficient asset management: a practical guide to stock portfolio optimization and asset allocation, Oxford University Press, Oxford, 2008), to evaluate whether US international equity closed-end funds (CEF) provide out-of-sample diversification benefits. My study finds that international $\mathrm{CEF}$ do not provide diversification benefits across the whole sample period. However, the out-of-sample diversification benefits of international CEF do vary across economic states. I find that there are significant diversification benefits when the lagged one-month US Treasury Bill return is lower than normal, and when higher than normal, regardless of the benchmark investment universe used.
\end{abstract}

Keywords Diversification benefits $\cdot$ Resampled portfolio efficiency ${ }^{\mathrm{TM}} \cdot$ Closed-end funds

\section{JEL Classification G11 - G12}

\section{I Introduction}

Ever since the classic studies of Grubel (1968), Lessard (1973), Solnik (1974), there have been strong arguments for international diversification. Although investors can invest directly in these markets, a more likely route, especially for retail investors is to invest indirectly through managed funds, such as international equity closed-end funds (CEF), open-end mutual funds, and exchange-traded funds (ETF). Parwada and Siaw (2014) find an increase in institutional investor ownership of US CEF shares through 1990 and 2010, and institutional ownership is largest in international

Jonathan Fletcher

j.fletcher@strath.ac.uk

1 Department of Accounting and Finance, University of Strathclyde, Stenhouse Wing, 199

Cathedral Street, Glasgow G4 0QU, UK 
CEF. Parwada and Siaw find that institutional investors tend to invest in CEF that provide exposure to asset classes that the institution does not concentrate in.

In this study, I examine the diversification benefits of US international equity CEF. CEF offer a number of advantages to investors. CEF can provide liquidity benefits to investors (Cherkes et al. 2009), are able to use leverage (Elton et al. 2013), do not need to engage in liquidity trading due to cash inflows and outflows (Edelen 1999), and can also hold less cash. Giannetti and Kahraman (2018) find that US domestic equity CEF invest more in underpriced stocks, especially stocks with high arbitrage risk, compared to domestic equity open-end mutual funds. CEF do, however, have higher agency costs than open-end mutual funds (Fama and Jensen(1983)), as CEF investors cannot sell their shares at NAV.

A number of studies examine the diversification benefits of international CEF and also compare to alternative home-based international investment vehicles such as ETFs, ADR's, open-end funds, and multinational companies. Bekaert and Uras (1996) find that UK emerging market funds provide diversification benefits but US emerging market funds do not. Bekaert and Urias (1999) find for the 1993 and 1996 period, that US emerging market CEF and open-end funds, and ADRs all provide significant diversification benefits. Errunza et al. (1999) also highlight the diversification benefits of investing in multinational companies, international country CEF, and ADR. Cao et al. (2017) find that iShares do not eliminate the diversification benefits of CEF. Fletcher (2018) finds for UK international CEF that both international CEF and ETF play an important role in international diversification. This literature suggests that international $\mathrm{CEF}$ continue to be useful in providing diversification benefits.

A downside of these studies is that they often ignore market frictions such as portfolio constraints and focus on in-sample diversification benefits. In this study, I use the simulation approach pioneered by Jobson and Korkie (1981) to examine the out-of-sample diversification benefits of US international equity CEF in the presence of market frictions. I use Michaud optimization based on resampled portfolio efficiency ${ }^{\mathrm{TM}}$ (Michaud and Michaud 2008) to form the optimal portfolios. ${ }^{1}$ The attraction of using Michaud optimization is that it takes account of the estimation error in the mean-variance inputs when building optimal portfolios, and leads to more diversified portfolios with less extreme weights (Michaud 1989). The Michaud optimization imposes no short selling constraints and the impact of trading costs can also be incorporated.

I examine the out-of-sample diversification benefits of US international equity closed-end funds (CEF) between January 1994 and October 2019 in the presence of market frictions. I use three different benchmark investment universes, which includes either six size/book-to-market (BM) portfolios, ten industry portfolios, or three domestic equity CEF portfolios. I examine the impact of adding international equity CEF to the benchmark universe using the Certainty Equivalent Return (CER) as the main performance measure to evaluate the out-of-sample diversification benefits. I also examine whether the out-of-sample diversification benefits varies across

\footnotetext{
1 See Michaud and Michaud (2008) for a textbook treatment of Michaud optimization.
} 
economic states. I use the dummy variable approach of Ferson and Qian (2004) and the lagged one-month US Treasury Bill return as the information variable (Fama and Schwert 1977; Ferson 1989; Dimson et al. 2016) to allocate each month to one of three economic states. The states are when the lagged one-month Treasury Bill return is lower than normal (Low), Normal, and higher than normal (High).

There are three main findings in my study. First, the international CEF do not provide out-of-sample diversification benefits across the whole sample period. This finding holds across all benchmark investment universes. Second, the out-of-sample diversification benefits of international CEF varies across economic states. The benefits are concentrated when the lagged one-month US Treasury Bill is lower than normal or higher than normal. Third, different investment sectors of international CEF drive the diversification benefits in the Low and High states. My paper suggests that international CEF do provide significant out-of-sample diversification benefits in certain economic states.

There are two main contributions of my study. First, I extend the prior studies of Bekaert and Urias (1996), Errunza et al. (1999), Cao et al. (2017) among others by focusing on the out-of-sample diversification benefits of the international equity CEF. Second, my study complements studies looking at international diversification benefits such as Li et al. (2003), Hodrick and Zhang (2014), Liu (2016) among others by focusing on the diversification benefits of international managed funds.

The paper is organized as follows. Section II presents the research method. Section III describes the data used in my study. Section IV reports the empirical results. The final section concludes.

\section{Research method}

The Markowitz (1952) approach to optimal portfolio selection with no short selling constraints, using the notation of Best and Grauer (1990), assumes that the investor with a given risk tolerance $(t)$ selects the optimal weights $\left(x_{i}\right)$ for the $N$ risky assets to:

$$
\text { Max tu - (1/2) } x^{\prime} V x
$$

subject to $x^{\prime} e=1$, and $x_{i} \geq 0$ for $i=1, \ldots, N$. where $\mathrm{x}$ is the $(N, 1)$ vector of optimal weights, $V$ is the $(N, N)$ covariance matrix, $u$ is a $(N, 1)$ vector of expected gross returns $(1+$ returns), and $e$ is a $(N, 1)$ vector of ones. When $t=0$, the optimal portfolio is the Global Minimum Variance (GMV) portfolio. As $t$ increases, we move further up the mean-variance frontier until we reach the point of the asset with the maximum expected return. The solution in Eq. (1) is equivalent to an alternative formulation of the mean-variance problem given by the maximum of $x^{\prime} u-(\gamma / 2) x^{\prime} V x$, where $\gamma$ is the risk aversion level of the investor, with $t=1 / \gamma$.

In this study, I am interested in the diversification benefits of international equity CEF. I start with a benchmark investment universe, which contains domestic equity portfolios. I then add international CEF portfolios to form an augmented investment universe and examine whether there is a significant shift in the mean-variance 
frontier. I use the simulation approach originally pioneered by Jobson and Korkie (1981) to evaluate the out-of-sample diversification benefits provided by international CEF. I use the simulation approach as it is commonly used in studies examining the out-of-sample performance of the mean-variance strategies such as Kan and Zhou (2007), Tu and Zhou (2011), Kan et al. (2021) among others. An alternative approach is to back-test portfolio strategies. Michaud et al. (2020) argue against back-testing as results are sample period specific. In contrast, with simulation a large number of realistic investment scenarios can be considered. A related issue is that a large of number of observations can be required to find statistically significant results. $^{2}$

The Monte Carlo simulation runs as follows. Define $M$ as the number of assets in the benchmark investment universe and $K$ is the number of international CEF portfolios, where $N=M+K$. First, $I$ estimate the sample moments of the $N$ risky assets and assume that the estimates are the true values $u_{\text {true }}$ and $V_{\text {true }}$. Second, $I$ draw $T$ simulated returns from the MVN $\left(u_{\text {true }}, V_{\text {true }}\right)$ distribution, ${ }^{3}$ where MVN is the multivariate normal distribution. I calculate the sample moments $u_{s}$ and $V_{s}$ from the simulated returns. Third, I solve the optimal portfolios in the benchmark investment universe and augmented investment universes using Michaud optimization. Michaud optimization is based on resampled portfolio efficiency ${ }^{\mathrm{TM}}$ (Michaud and Michaud 2008). Michaud optimization provides a way to incorporate the impact of estimation error in the mean-variance inputs and leads to more diversified, and stable optimal portfolios. An additional advantage of Michaud optimization is that the optimal weights are a lot less sensitive to the inputs of the mean-variance optimization. ${ }^{4}$ Using Michaud optimization does not imply that these strategies always generate better out-of-sample performance than the Markowitz portfolios (Michaud and Esch 2018). In these cases, we can view the use of Michaud optimal portfolios as providing a conservative test of the out-of-sample diversification benefits.

I solve the optimal portfolios using Michaud optimization as follows. First, I draw $T$ simulated returns for the $N$ risky assets from a multivariate normal distribution using the inputs $u_{s}$ and $V_{s}$. Second, I calculate the sample moments from the simulated gross returns and estimate the mean-variance frontiers based on these inputs subject to the budget constraint and no short selling constraints for both the benchmark and augmented investment universes. I select three different optimal portfolios from the two mean-variance frontiers for investors with different risk tolerance levels. I set $t=0\left(\mathrm{GMV}_{\mathrm{B}}, \mathrm{GMV}\right), t=0.2\left(\right.$ Middle $\left._{\mathrm{B}}, \mathrm{Middle}\right)$, and $t=0.5\left(\mathrm{High}_{\mathrm{B}}, \mathrm{High}\right)$. Third, I repeat steps 1 and 2, 1000 times, and the optimal RE $\mathrm{GMV}_{\mathrm{B}}$, Middle $_{\mathrm{B}}$, $\mathrm{High}_{\mathrm{B}}$, GMV, Middle, and High portfolios are given by the average weights of the 1000 corresponding optimal portfolios. The fourth step in the Monte Carlo simulation of Jobson and Korkie (1981) is to use the optimal portfolio weights from the Michaud optimization and calculate the mean gross return $\left(u_{\text {pout }}\right)$, and standard

\footnotetext{
${ }^{2}$ We can of course view the two approaches as being complementary to one another.

3 I could use a multivariate $\mathrm{t}$-distribution or bootstrapping.

4 Best and Grauer (1991) highlight the extreme sensitivity of constrained mean-variance portfolio weights to changes in expected returns.
} 
deviation $\left(\sigma_{\text {pout }}\right)$ using the $u_{\text {true }}$ and $V_{\text {true }}$ inputs, which captures the out-of-sample return and risk of the optimal portfolios. I repeat steps 1-4, 1,000 times.

The main performance measure I use to evaluate the diversification benefits is based on the CER measure. I calculate the change in CER performance (DCER) between the optimal portfolio in the benchmark universe (B) and the augmented universe (A). The DCER measure is calculated as:

$$
\mathrm{DCER}=\left[\left(u_{\text {pout }}-R f\right)-(\gamma / 2) \sigma_{\text {pout }}^{2}\right]_{A}-\left[\left(u_{\text {pout }}-R f\right)-(\gamma / 2) \sigma_{\text {pout }}^{2}\right]_{B}
$$

where $\gamma$ is the risk aversion of the investor and $R f$ is the risk-free return. I use the mean return on the one-month US Treasury Bill as Rf. I compare the GMV and $\mathrm{GMV}_{\mathrm{B}}$, Middle and Middle $_{\mathrm{B}}$, and High and $\mathrm{High}_{\mathrm{B}}$ portfolios. I use the average outof-sample DCER measure to estimate the diversification benefits of international CEF. Under the null hypothesis of no diversification benefits, the average DCER measure equals 0 . I examine statistical significance of the average DCER $>0$, when the $5 \%$ and $10 \%$ percentiles of the DCER measure are positive. I calculate DCER using $\gamma=2$ and $\gamma=5$, but only report the $\gamma=5$ results but will discuss where there are any differences.

I also calculate the mean out-of-sample average return $\left(r_{p}\right)$ and volatility $\left(\sigma\left(r_{p}\right)\right)$. Ledoit and Wolf (2017) argue that the out-of-sample volatility is a more relevant metric when comparing the performance of GMV portfolios. Using $r_{p}$ and $\sigma\left(r_{p}\right)$, I also calculate the Sharpe (1966) performance as $\left(r_{p}-R f\right) / \sigma\left(R_{p}\right)$. The simulation analysis produces the out-of-sample distribution of the optimal portfolio weights. If the international CEF provides diversification benefits, I would expect to find the dominant assets in the optimal portfolios to be in the international CEF portfolios.

The analysis so far examines the out-of-sample unconditional diversification benefits of international CEF portfolios. I use the dummy variable approach of Ferson and Qian (2004) to examine the out-of-sample diversification benefits of international CEF across economic states. Ferson and Qian point out that the dummy variable approach has a number of advantages. First, it avoids the use of a linear functional form of the lagged information variables. Second, it identifies each month to a given state ex ante by only using information available prior to that month. This approach differs from using NBER recession and expansion states which are only known ex post. Third, it reduces the spurious regression bias of highly persistent lagged information variables highlighted in Ferson et al. (2003).

I identify the economic states as follows. Define $z_{t-1}$ as the value of the lagged information variable at time $t-1, x_{t-1}$ is $z_{t-1}$ minus the prior 60 -month average of $z_{t-1}$, and $\sigma\left(z_{t-1}\right)$ is the standard deviation of $z_{t-1}$ over the prior sixty months. I allocate each month in our sample period to one of the three states depending on the value of $x_{t-1} / \sigma\left(z_{t-1}\right)$. A Low state month is when $x_{t-1} / \sigma\left(z_{t-1}\right)<-1$. A High state month is when $x_{t-1} / \sigma\left(z_{t-1}\right)>1$. A Normal state month is when $-1<x_{t-1} / \sigma\left(z_{t-1}\right)<1$. I create three dummy variables, ${ }^{5}$ which equals 1 if a month is in a given state and 0 otherwise. I then use the Monte Carlo simulation approach with the Michaud optimization to evaluate the out-of-sample

\footnotetext{
${ }^{5}$ Using more than three states would reduce the number of observations in each state.
} 
diversification benefits in the different economic states. I use the sample moments from each state as the true values $u_{\text {true }}$ and $V_{\text {true }}$ in these tests.

The Low and Normal states have a fairly even split of the NBER recession dates. The Normal state picks up the majority of months where the domestic US excess market returns are negative. The Low and High states pick up a similar number of months with negative excess market returns. The main periods for the Low state are between June 2001 and July 2004 and November 2008 and January 2011 and so picking up periods of strong market performance as well as downturns. The Normal state include April 1994 and July 2000, October 2007 and October 2008, as well as February 2011 and December 2015 and so picking up the main part of the financial crisis. The main periods of the High state include August 2000 and February 2001, December 2005 and September 2007, and July 2016 onwards and so picking up part of the dot.com bubble and financial crisis.

\section{Data}

\subsection{Sample of international closed-end equity funds}

I evaluate the diversification benefits of US international equity closed-end funds (CEF) between January 1994 and October 2019. I identify my initial sample of funds from Morningstar Direct. CEF are traded on stock exchanges and their returns are available on different databases along with other stocks. I select all US closedend funds with a Morningstar international equity category. I collect the monthly stock returns ${ }^{6}$ and Morningstar categories for each fund from Morningstar. All of the returns are in US \$.

I group all international CEF into the following investment sectors:

1. Global - this sector includes funds in the World Large, World Small/Mid, Foreign Large Growth, Foreign Large Blend, Foreign Large Value, Foreign Small/Mid Growth, Foreign Small/Mid Blend, and Foreign Small/Mid Value Morningstar categories.

2. Emerging Markets (EM) — this sector includes Diversified Emerging Markets, Latin America, China Region, and India Equity Morningstar categories.

3. Asia Pacific — this portfolio includes funds with Diversified Pacific/Asia, Pacific/ Asia ex Japan Stock, and Japan Morningstar categories.

4. Europe-this sector includes funds in the Europe Morningstar category.

\footnotetext{
${ }^{6}$ Using monthly stock returns implies that the focus is on the value added provided by CEF. The value added by CEF depends upon the performance ability of the funds, trading costs and expenses, and the behavior of the CEF discount/premium. Rational explanations of the CEF discount include Berk and Stanton (2007), Cherkes et al (2009), Jarrow and Protter (2019).
} 
For funds in the Miscellaneous Region category, I allocate to one of the categories 2-4 depending upon region and whether developed or emerging markets.

For each of the four investment sectors, I form an equal weighted (EW) portfolio. At start of each month between January 1994 and October 2019, I group all CEF with a Morningstar international equity category from the end of the previous month and group into the four portfolios. I then calculate the monthly return of the portfolios during the next month as the average monthly return of all funds with a return observation in that month. The use of CEF portfolios mitigates the survivorship bias and look-ahead bias (Carhart et al. 2002) as the CEF portfolios include funds with even a small number of return observations.

\subsection{Benchmark assets}

I use three groups of benchmark assets. The first two groups are used in the mutual fund performance study of Chretien and Kammoun (2017) and consist of six size/ book-to-market (BM) portfolios underlying the Fama and French (1993) factors and ten industry portfolios. The industry portfolios include Non-Durables (NonDur), Durables (Durbl), Manufacturing (Manuf), Energy (Enrgy), High Technology (HiTec), Telecommunications (Telcm), Shops, Health (Hlth), Utilities (Utils), and Other. I collect the monthly returns of the size/BM portfolios and industry portfolios from Ken French's Data Library.

The final set of benchmark assets follows from Bekaert and Urias (1996) ${ }^{7}$ and includes domestic equity CEF. I form three domestic equity $\mathrm{CEF}$ portfolios. The sectors include:

1. Small-this sector includes all funds in the Small Growth, Small Blend and Small Value Morningstar categories.

2. Mid - this sector includes all funds in the Mid Growth, Mid Blend, and Mid Value Morningstar categories.

3. Large - this sector includes all funds in the Large Growth, Large Blend, and Large Value Morningstar categories.

I form EW portfolios of domestic equity CEF following the same approach as the international CEF portfolios.

Table 1 reports summary statistics of the benchmark assets and the CEF portfolios. The summary statistics include the mean, standard deviation (Std Dev), minimum, and maximum monthly gross returns $(1+$ returns $)$ of the benchmark assets (panel A) and the international CEF portfolios (panel B).

Panel A of Table 1 shows that there is a narrow range in the mean returns of the size/BM portfolios. The mean returns range between $0.777 \%$ (Small/Growth) and $1.095 \%$ (Small/Value). There is only a value effect in Small companies. There is a likewise a narrow range in the mean returns of the industry portfolios. The mean

\footnotetext{
7 I am grateful for a reviewer suggesting this choice.
} 
Table 1 Summary statistics of benchmark assets and CEF portfolios

\begin{tabular}{|c|c|c|c|c|}
\hline & Mean & SD & Minimum & Maximum \\
\hline \multicolumn{5}{|l|}{ Panel A } \\
\hline \multicolumn{5}{|l|}{ Size/BM } \\
\hline Small/Growth & 1.00777 & 6.66220 & 0.75531 & 1.27086 \\
\hline Small/Neutral & 1.01070 & 5.18453 & 0.80799 & 1.16618 \\
\hline Small/Value & 1.01095 & 5.47003 & 0.79502 & 1.17287 \\
\hline Big/Growth & 1.00944 & 4.22937 & 0.85007 & 1.10053 \\
\hline Big/Neutral & 1.00872 & 4.25448 & 0.82056 & 1.12365 \\
\hline Big/Value & 1.00857 & 5.16077 & 0.77733 & 1.17658 \\
\hline \multicolumn{5}{|l|}{ Industry } \\
\hline NonDur & 1.00894 & 3.56548 & 0.87010 & 1.10800 \\
\hline Durbl & 1.00667 & 6.89751 & 0.67370 & 1.42630 \\
\hline Manuf & 1.01001 & 4.76674 & 0.79250 & 1.17510 \\
\hline Enrgy & 1.00829 & 5.69108 & 0.82770 & 1.19030 \\
\hline Hi Tec & 1.01189 & 6.99094 & 0.74040 & 1.20760 \\
\hline Telcm & 1.00714 & 5.08845 & 0.83650 & 1.21360 \\
\hline Shops & 1.00939 & 4.37106 & 0.84880 & 1.13280 \\
\hline Hlth & 1.01009 & 4.18874 & 0.87740 & 1.12000 \\
\hline Utils & 1.00820 & 3.97152 & 0.87350 & 1.11720 \\
\hline Other & 1.00831 & 5.07558 & 0.78640 & 1.16360 \\
\hline \multicolumn{5}{|l|}{ Domestic CEF } \\
\hline Small & 1.00925 & 5.68306 & 0.74890 & 1.15783 \\
\hline Mid Cap & 1.00784 & 4.41129 & 0.74517 & 1.16183 \\
\hline Large & 1.00887 & 4.40130 & 0.80935 & 1.14864 \\
\hline \multicolumn{5}{|l|}{ Panel B: } \\
\hline \multicolumn{5}{|l|}{ CEF Portfolios } \\
\hline Global & 1.00871 & 6.24822 & 0.68293 & 1.25096 \\
\hline EM & 1.00896 & 6.94414 & 0.70338 & 1.21386 \\
\hline Asia Pacific & 1.00580 & 6.93130 & 0.73337 & 1.27246 \\
\hline Europe & 1.00829 & 6.62034 & 0.69055 & 1.24013 \\
\hline
\end{tabular}

The table reports summary statistics of the monthly gross returns $(1+$ returns $)$ of the benchmark assets, and international CEF portfolios between January 1994 and October 2019. The summary statistics for the size/BM portfolios, industry portfolios, and domestic equity CEF portfolios (panel A), and international CEF portfolios (panel B) includes the mean, standard deviation (SD,\%), minimum, and maximum monthly gross returns

returns range between $0.667 \%$ (NonDur) and $1.189 \%$ (HiTec). There is a wider spread in the volatility of industry portfolios compared to the size/BM portfolios. The NonDur industry has the lowest volatility and HiTec industry has the highest volatility. Among the domestic equity CEF portfolios, the Small portfolio has the highest mean return and volatility. The Large portfolio has the lowest volatility.

Panel B of Table 1 shows that the mean returns of the international equity CEF portfolios range between $0.580 \%$ (Asia Pacific) and $0.896 \%$ (EM). The EM CEF 
portfolio likewise has the highest volatility. One noticeable difference between the international CEF portfolios and the benchmark assets is that the volatility of the international CEF is higher in the vast majority of cases than the benchmark assets, with a wider range between the minimum and maximum monthly returns.

\subsection{Lagged information variable}

To evaluate the diversification benefits of the international CEF across economic states, I use the lagged one-month US Treasury Bill return (see Fama and Schwert 1977; Ferson 1989) as $z_{t}$ to form the dummy variables for the three states. The short interest rate has been used in a number of mutual fund performance studies such as Ferson and Schadt (1996) and Ferson and Qian (2004) among others. ${ }^{8}$ Dimson et al. (2016) show that the short interest rate has significant predictive ability in different risky asset returns. The three economic states are when the lagged one-month Treasury Bill return is lower than normal (Low), Normal, and higher than normal (High). Table 2 reports the mean returns of the benchmark assets (panel A) and international CEF portfolios (Panel B) in the three states. The table also includes the $t$-statistic of Ferson et al. (2006b) that examines the null hypothesis that the mean returns between two states are equal to one another. In unreported tests, I also estimate the median return ${ }^{9}$ in each state and the correlation matrix between all the benchmark assets together and CEF portfolios in each state.

Panel A shows that Small and Big portfolios have a different pattern in mean returns across economic states. The Small portfolios have their highest mean returns in the Low state. The mean returns of the Big portfolios are highest in the High state. A similar pattern exists in the median returns as well, except for the Big/Value portfolio. The volatility of the Small and Big portfolios are likewise highest in the Low state. Perez-Quiros and Timmermann (2000) find that the relation between mean returns across states is a lot stronger in small companies as they are more affected by economic downturns. The main evidence of statistical significance between mean returns of different states is for the Small portfolios and the Low and Normal states. There is a strong size effect in the Low state and a reversal in the size effect in the High state, except for the Neutral BM portfolios. This pattern is consistent with the long-run performance of the size premiums in Dimson et al. (2016). Dimson et al. also find that the value premium is stronger after interest rate falls compared to after interest rates rise, which is consistent with the relative average returns between the Value and Growth portfolios in Table 2.

The patterns in mean returns across economic states vary across industry portfolios. For some industries, the mean returns are highest in the Low state, such as Durbl, Hi Tec, and Shops. For other industries, the mean returns are highest in the High state, such as NonDur, Manuf, Telcm, Hlth, Utils, and Other.

\footnotetext{
8 See also Perez-Quiros and Timmermann (2000).

${ }^{9}$ I use the Wilcoxon signed rank test statistic to examine whether the median returns between two states are equal.
} 
Table 2 Summary statistics of benchmark assets and CEF portfolios across economic states

\begin{tabular}{|c|c|c|c|c|c|c|}
\hline & Low & Normal & High & $t_{\mathrm{HL}}$ & $t_{\mathrm{HN}}$ & $t_{\mathrm{LN}}$ \\
\hline \multicolumn{7}{|l|}{ Panel A } \\
\hline \multicolumn{7}{|l|}{ Size/BM } \\
\hline Small/Growth & 1.01407 & 1.00490 & 1.00758 & -1.32 & 0.60 & $1.84^{\mathrm{b}}$ \\
\hline Small/Neutral & 1.01585 & 1.00759 & 1.01192 & -1.01 & 1.30 & $2.06^{\mathrm{a}}$ \\
\hline Small/Value & 1.01759 & 1.00741 & 1.01171 & -1.36 & 1.28 & $2.32^{\mathrm{a}}$ \\
\hline Big/Growth & 1.00858 & 1.00918 & 1.01065 & 0.66 & 0.53 & -0.18 \\
\hline Big/Neutral & 1.00849 & 1.00755 & 1.01100 & 0.83 & 1.28 & 0.28 \\
\hline Big/Value & 1.00278 & 1.00874 & 1.01317 & $2.54^{\mathrm{a}}$ & 1.46 & -1.40 \\
\hline \multicolumn{7}{|l|}{ Industry } \\
\hline NonDur & 1.00759 & 1.00898 & 1.01002 & 0.99 & 0.44 & -0.51 \\
\hline Durbl & 1.01888 & 1.00008 & 1.00819 & $-2.07^{\mathrm{a}}$ & $1.97^{\mathrm{a}}$ & $3.36^{\mathrm{a}}$ \\
\hline Manuf & 1.01397 & 1.00586 & 1.01414 & 0.04 & $2.75^{\mathrm{a}}$ & $2.17^{\mathrm{a}}$ \\
\hline Enrgy & 1.00802 & 1.00909 & 1.00706 & -0.25 & -0.49 & -0.27 \\
\hline Hi Tec & 1.01528 & 1.01184 & 1.00912 & -1.13 & -0.59 & 0.64 \\
\hline Telcm & 1.00486 & 1.00772 & 1.00802 & 0.80 & 0.09 & -0.70 \\
\hline Shops & 1.01150 & 1.00816 & 1.00981 & -0.52 & 0.59 & 0.97 \\
\hline Hlth & 1.00233 & 1.01193 & 1.01334 & $3.73^{\mathrm{a}}$ & 0.48 & $-3.19^{a}$ \\
\hline Utils & 1.00125 & 1.00835 & 1.01380 & $4.37^{\mathrm{a}}$ & $2.07^{\mathrm{a}}$ & $-2.39^{a}$ \\
\hline Other & 1.00737 & 1.00750 & 1.01056 & 0.87 & 0.96 & -0.03 \\
\hline \multicolumn{7}{|l|}{ Domestic CEF } \\
\hline Small & 1.01448 & 1.00580 & 1.01102 & -0.82 & 1.43 & $1.96^{\mathrm{a}}$ \\
\hline Mid Cap & 1.00926 & 1.00375 & 1.01401 & 1.46 & $3.44^{\mathrm{a}}$ & $1.70^{\mathrm{b}}$ \\
\hline Large & 1.00971 & 1.00664 & 1.01218 & 0.75 & $2.02^{\mathrm{a}}$ & 0.87 \\
\hline \multicolumn{7}{|l|}{ Panel B: } \\
\hline \multicolumn{7}{|l|}{ CEF Portfolios } \\
\hline Global & 1.01898 & 1.00309 & 1.01011 & $-1.90^{b}$ & $1.84^{\mathrm{b}}$ & $3.18^{\mathrm{a}}$ \\
\hline EM & 1.01897 & 0.99894 & 1.01852 & -0.09 & $4.30^{\mathrm{a}}$ & $3.84^{\mathrm{a}}$ \\
\hline Asia Pacific & 1.02097 & 0.99409 & 1.01404 & -1.42 & $4.50^{\mathrm{a}}$ & $5.10^{\mathrm{a}}$ \\
\hline Europe & 1.02067 & 1.00060 & 1.01160 & $-1.85^{\mathrm{b}}$ & $2.71^{\mathrm{a}}$ & $3.80^{\mathrm{a}}$ \\
\hline
\end{tabular}

${ }^{\text {a }}$ Significant at $5 \%$

${ }^{\mathrm{b}}$ Significant at $10 \%$

The table reports summary statistics of the benchmark assets and international equity CEF portfolios across three economic states between January 1994 and October 2019. The summary statistics include the mean monthly gross returns $(1+$ returns $)$. The economic states are given by when the lag one-month US Treasury Bill return is lower than normal (Low), Normal, and higher than normal (High). The final three columns report $t$-statistics of the null hypothesis of the mean returns between two states are equal to one another. The $t$-statistics are calculated for the High and Low states (HL), High and Normal states (HN), and Low and Normal states (LN). Panel A refers to the benchmark assets including the size/BM portfolios, industry portfolios, and domestic equity CEF portfolios, and panel B refers to the international CEF portfolios 
These patterns are in the main consistent with Dimson et al. (2016). It is only the Durbl, Manuf, Hlth, and Utils industry portfolios where there are significant differences in mean returns between economic states. The Durbl and Manuf portfolios also have a large variation in the median returns across states but the differences are not statistically significant. The volatility of the industry portfolios, with the exception of Enrgy, is highest in the Low state.

The domestic CEF portfolios follow a similar pattern to the size/BM portfolios. The Small CEF portfolio has the highest mean return in the Low state and the Mid Cap and Large CEF portfolios have the highest mean returns in the High state. There are significant differences in the mean returns between High and Normal states for the Mid Cap and Large CEF portfolios and between Low and Normal states for the Small and Mid Cap CEF portfolios. There is a much wider spread in the median returns of the domestic CEF portfolios, especially for the Small CEF portfolio but the differences in the median returns are only statistically significant for the High and Normal states using the Mid Cap portfolio. As with the other benchmark assets, the volatility of the domestic CEF portfolios is largest in the High state.

Panel B of Table 2 shows that there is greater predictability in the mean returns of the international $\mathrm{CEF}$ portfolios. The range in mean returns across states are generally a lot wider in the international CEF portfolios compared to the benchmark assets. The mean returns of the international CEF portfolios are highest in the Low state and poorest in the Normal state. There are significant differences in mean returns at the $10 \%$ level between High and Normal states, and Low and Normal states. There are significant differences between the High and Low states for the Global and Europe CEF portfolios. There is a similar pattern in the median returns. There is also likewise a wide variation in the volatility of the international CEF portfolios across economic states. The volatility of international CEF portfolios is highest in the Low state and lowest in the High state. The pattern of volatility across both the benchmark assets and international CEF portfolios being largest in the Low state is consistent with Dimson et al. (2016).

The average correlations between the benchmark assets and international CEF portfolios are lowest in the High state and highest in the Low state. The highest average correlation in the Low state is driven by the higher volatility of the benchmark assets and CEF portfolios in that state. The correlations between the benchmark assets and CEF portfolios in the Low state have a narrow range between 0.428 and 0.965 . In contrast, in the High state the correlations range between -0.241 and 0.968 .

\section{Empirical results}

I begin my empirical analysis by illustrating the differences between Markowitz and Michaud optimization. Using the sample moments, I estimate the optimal portfolios for the three risk tolerance levels and three benchmark universes. For the GMV $(t=0)$, the Markowitz and Michaud optimal portfolios are similar as in 
Michaud and Michaud (2008). For $t=0.2$ and $t=0.5$, there are substantial differences in the optimal portfolio weights. The Markowitz optimal portfolios tend to be concentrated in a small number of assets, where the Michaud optimal portfolios are a lot more diversified and imply an investment in nearly all assets.

I next examine whether international CEF provide out-of-sample diversification benefits across the whole sample period by running the Michaud optimization, where the number of simulated return observations is set equal to the whole sample period and $\mathrm{Rf}$ is the mean one-month US Treasury Bill return across the whole sample period. Table 3 reports summary statistics of the out-of-sample performance using the size/BM (panel A), industry (panel B), and domestic CEF portfolios (panel C) as the benchmark investment universe. The summary statistics include the mean, standard deviation (Std Dev), 5\% and 10\% percentiles, and the median of the DCER (\%) measure. The next three rows in each panel includes the mean out-of-sample average return $\left(\mathrm{r}_{\mathrm{p}}\right)$, volatility $\left(\sigma\left(\mathrm{r}_{\mathrm{p}}\right)\right)$, and corresponding Sharpe performance. The final row includes the mean of the absolute deviation of the optimal portfolio weights from an equal weighted strategy (Ledoit and Wolf 2017). To conserve space, I do not report summary statistics of the optimal portfolio weights, but will discuss in the text.

Table 3 shows that international CEF do not provide out-of-sample diversification benefits across the whole sample period. This finding holds across all benchmark investment universes. All of the mean DCER measures are negative but small. The GMV, Middle, and High portfolios all provide a lower Sharpe performance than the $\mathrm{GMV}_{\mathrm{B}}$, Middle $_{\mathrm{B}}$, and $\mathrm{High}_{\mathrm{B}}$ portfolios but the differences are not large. The optimal GMV, Middle, and High portfolio do require a lot deviation from an equal weighted index compared to the $\mathrm{GMV}_{\mathrm{B}}$, Middle ${ }_{\mathrm{B}}$, and $\mathrm{High}_{\mathrm{B}}$ portfolios. The differences are largest when the benchmark universe is the domestic CEF portfolios.

The optimal portfolio weights in the GMV, Middle, and High portfolios show that the vast majority of the portfolio are in the benchmark assets. In the GMV portfolio, there are no significant mean weights in the international CEF portfolios. In the Middle portfolios, there are no significant mean weights in the international CEF portfolios using the size/BM or industry portfolios as the benchmark universe. In the domestic CEF benchmark universe, there are small significant mean weights in the Global and EM CEF portfolios. The Global and EM CEF portfolios also have significant mean weights in the High portfolio when the benchmark universe is the size/BM or domestic CEF portfolios but the combined exposure to the international CEF remains relatively small. The pattern in optimal portfolio weights is consistent with the lack of diversification benefits in Table 3 .

The analysis in Table 3 uses the multivariate normal distribution to generate the simulated return data. I examine the robustness of this approach and use bootstrapping to generate the simulated data. I run the tests using the size/BM portfolios as the benchmark universe and resample the data with replacement to generate the simulated return data. I find similar results to panel A of Table 3.

I next examine whether international CEF provide out-of-sample diversification benefits across economic states. I run the tests for the Low, Normal, and High states, where the number of simulated returns is set equal to the number of observations in that state and $\mathrm{Rf}$ is set equal to the mean one-month Treasury Bill 
Table 3 Out-of-sample performance

\begin{tabular}{|c|c|c|c|c|c|c|}
\hline & Mean & SD & $5 \%$ & $10 \%$ & Median & \\
\hline \multicolumn{7}{|c|}{ Panel A: } \\
\hline \multicolumn{7}{|l|}{ Size/BM } \\
\hline \multicolumn{7}{|c|}{$\operatorname{DCER}(\gamma=5)$} \\
\hline GMV & -0.002 & 0.004 & -0.011 & -0.007 & -0.001 & \\
\hline Middle & -0.029 & 0.040 & -0.107 & -0.077 & -0.014 & \\
\hline \multirow[t]{2}{*}{ High } & -0.072 & 0.093 & -0.269 & -0.190 & -0.035 & \\
\hline & $\mathrm{GMV}_{\mathrm{B}}$ & Middle $_{B}$ & $\operatorname{High}_{B}$ & GMV & Middle & High \\
\hline$r_{p}$ & 1.00914 & 1.00974 & 1.01002 & 1.00912 & 1.00962 & 1.00973 \\
\hline$\sigma\left(r_{p}\right)$ & 4.07420 & 4.34948 & 4.61493 & 4.07807 & 4.42925 & 4.79614 \\
\hline Sharpe & 0.176 & 0.178 & 0.174 & 0.175 & 0.172 & 0.161 \\
\hline MAD & 1.288 & 0.996 & 0.984 & 1.541 & 1.181 & 1.112 \\
\hline \multicolumn{7}{|l|}{ Panel B: } \\
\hline \multicolumn{7}{|c|}{ Industry } \\
\hline \multicolumn{7}{|c|}{$\operatorname{DCER}(\gamma=5)$} \\
\hline GMV & -0.004 & 0.004 & -0.014 & -0.010 & -0.002 & \\
\hline Middle & -0.016 & 0.023 & -0.059 & -0.041 & -0.007 & \\
\hline \multirow[t]{2}{*}{ High } & -0.035 & 0.056 & -0.150 & -0.097 & -0.013 & \\
\hline & $\mathrm{GMV}_{\mathrm{B}}$ & Middle $_{\mathrm{B}}$ & $\mathrm{High}_{\mathrm{B}}$ & GMV & Middle & High \\
\hline$r_{p}$ & 1.00893 & 1.00949 & 1.00985 & 1.00889 & 1.00940 & 1.00968 \\
\hline$\sigma\left(r_{p}\right)$ & 3.17163 & 3.62254 & 4.15237 & 3.17465 & 3.66330 & 4.24428 \\
\hline Sharpe & 0.219 & 0.207 & 0.189 & 0.218 & 0.203 & 0.181 \\
\hline MAD & 1.141 & 1.044 & 1.092 & 1.341 & 1.177 & 1.175 \\
\hline \multicolumn{7}{|c|}{ Panel C: } \\
\hline \multicolumn{7}{|c|}{ Domestic CEF } \\
\hline \multicolumn{7}{|c|}{$\operatorname{DCER}(\gamma=5)$} \\
\hline GMV & -0.005 & 0.006 & -0.018 & -0.013 & -0.003 & \\
\hline Middle & -0.033 & 0.042 & -0.115 & -0.082 & -0.018 & \\
\hline \multirow[t]{2}{*}{ High } & -0.094 & 0.107 & -0.320 & -0.253 & -0.057 & \\
\hline & $\mathrm{GMV}_{\mathrm{B}}$ & Middle $_{\mathrm{B}}$ & $\mathrm{High}_{\mathrm{B}}$ & GMV & Middle & High \\
\hline$r_{p}$ & 1.00837 & 1.00862 & 1.00876 & 1.00832 & 1.00857 & 1.00866 \\
\hline$\sigma\left(r_{p}\right)$ & 4.19985 & 4.37467 & 4.58542 & 4.20575 & 4.50194 & 4.93337 \\
\hline Sharpe & 0.152 & 0.152 & 0.148 & 0.151 & 0.146 & 0.135 \\
\hline MAD & 0.670 & 0.722 & 0.676 & 1.386 & 1.100 & 0.975 \\
\hline
\end{tabular}

The table reports summary statistics of the out-of-sample performance using Michaud optimization. Two sets of RE portfolios are estimated. The first set uses a benchmark investment universe consisting of the returns of domestic assets of either six size/BM portfolios (panel A), ten industry portfolios (panel B), and three domestic equity CEF portfolios (panel C). The second set is the augmented investment universe, which adds four international equity CEF portfolios to the benchmark investment universe. Three $\mathrm{RE}$ portfolios are formed from the benchmark investment universe $\left(\mathrm{GMV}_{\mathrm{B}}, \mathrm{Middle}_{\mathrm{B}}\right.$, and $\left.\mathrm{High}_{\mathrm{B}}\right)$ and from the augmented investment universe (GMV, Middle, and High) using a risk tolerance level set equal to 0 (GMV), 0.2 (Middle), and 0.5 (High). The DCER measure (\%) is the change in CER performance between the GMV and $\mathrm{GMV}_{\mathrm{B}}$, Middle and Middle $\mathrm{B}_{\mathrm{B}}$, and High and $\mathrm{High}_{\mathrm{B}}$ strategies. The summary statistics of performance include the average, standard deviation (Std Dev), the 5\% and 10\% percentiles, and median of the DCER measure. The final rows of each panel include the average out-of-sample mean return $\left(r_{p}\right)$ and volatility $\left(\sigma\left(r_{p}\right)\right)$ of the strategies from the benchmark and augmented investment universes, the corresponding Sharpe performance, and the mean absolute deviation (MAD) of the optimal 
Table 3 (continued)

weights from an equal weighted strategy. The simulation uses the sample moments of the benchmark assets and international CEF portfolios during the January 1994 and October 2019 sample period as the true $\mathrm{u}$ and $\mathrm{V}$. The number of simulation trials is 1000 and the risk aversion $(\gamma)$ level for the DCER measure is set equal to 5

return in that state. In the Normal state, international CEF do not provide any outof-sample diversification benefits. The mean DCER measures are all negative. Tables 4, 5, 6 and 7 report the summary statistics of the out-of-sample performance and optimal portfolio weights in Low state (Tables 4 and 5) and the High state (Tables 6 and 7). The summary statistics of the optimal portfolio weights in the GMV, Middle, and High portfolios (Tables 5 and 7) include the mean and $10 \%$ percentile from the optimal weights.

Table 4 shows that the international CEF provide out-of-sample diversification benefits in the Low state for investors with higher risk tolerance levels. This finding is robust across all three benchmark universes. The GMV portfolio provides no diversification benefits in the Low state relative to the $\mathrm{GMV}_{\mathrm{B}}$ portfolio. The mean DCER measures of the Middle and High portfolios are all positive and significant at the $5 \%$ percentile. Likewise, the Middle and High portfolios provide a higher Sharpe performance than the Middle $_{B}$ and $\mathrm{High}_{\mathrm{B}}$ portfolios. The diversification benefits are driven by a higher mean out-of-sample average return. The GMV, Middle, and High portfolios do exhibit a greater deviation from the $1 / \mathrm{N}$ strategy compared to the $\mathrm{GMV}_{\mathrm{B}}$, Middle ${ }_{\mathrm{B}}$, and $\mathrm{High}_{\mathrm{B}}$ portfolios. The superior performance of the Middle and High portfolios is driven by the international CEF portfolios having their highest average returns in the Low state.

The optimal portfolio weights in Table 5 show that there is little exposure to the international CEF portfolios in the GMV portfolio. The mean weights of the international CEF portfolios are tiny and none are significant at the $10 \%$ percentile, which is consistent with the lack of diversification benefits by the GMV portfolio. For the Middle and High portfolios, there is a substantial exposure to the international $\mathrm{CEF}$ portfolios. All of the mean weights on the international CEF portfolios in the Middle and High portfolios are significant at the $10 \%$ percentile, with the exception of the EM CEF portfolio when the benchmark universe is the industry portfolios. This result suggests that all of the international CEF play some role in the diversification benefits in the Low state. The exposure to the international CEF portfolios increases as we move from the Middle to High portfolios. The Asia Pacific CEF portfolio has the largest mean weight in the Middle and High portfolios and the EM CEF portfolio has the lowest mean weight.

Table 6 shows that the international CEF provide out-of-sample diversification benefits in the High state. The main difference with Table 4 is that the GMV portfolio now provides significant diversification benefits when the benchmark investment universe is either the size/BM portfolios or the industry portfolios. The mean DCER measures of the GMV, Middle, and High portfolios are all positive and significant at the $5 \%$ percentile for the size/BM portfolios and industry portfolios benchmark 
Table 4 Out-of-sample performance: low state

\begin{tabular}{|c|c|c|c|c|c|c|}
\hline & Mean & SD & $5 \%$ & $10 \%$ & Median & \\
\hline \multicolumn{7}{|c|}{ Panel A: } \\
\hline \multicolumn{7}{|c|}{ Size/BM } \\
\hline \multicolumn{7}{|c|}{$\operatorname{DCER}(\gamma=5))$} \\
\hline GMV & 0.018 & 0.025 & 0.000 & 0.000 & 0.008 & \\
\hline Middle & 0.166 & 0.063 & 0.061 & 0.089 & 0.169 & \\
\hline \multirow[t]{2}{*}{ High } & 0.176 & 0.084 & 0.029 & 0.074 & 0.179 & \\
\hline & $\mathrm{GMV}_{\mathrm{B}}$ & Middle $_{B}$ & $\operatorname{High}_{B}$ & GMV & Middle & High \\
\hline$r_{p}$ & 1.00859 & 1.01413 & 1.01542 & 1.00884 & 1.01800 & 1.01907 \\
\hline$\sigma\left(r_{p}\right)$ & 4.89682 & 6.13525 & 6.64376 & 4.92215 & 6.82442 & 7.19607 \\
\hline Sharpe & 0.154 & 0.213 & 0.216 & 0.158 & 0.248 & 0.250 \\
\hline MAD & 1.344 & 1.003 & 1.097 & 1.551 & 1.064 & 1.173 \\
\hline \multicolumn{7}{|c|}{ Industry } \\
\hline \multicolumn{7}{|c|}{ Panel B: } \\
\hline \multicolumn{7}{|c|}{$\operatorname{DCER}(\gamma=5)$} \\
\hline GMV & 0.004 & 0.009 & 0 & 0 & 0.001 & \\
\hline Middle & 0.178 & 0.078 & 0.059 & 0.086 & 0.174 & \\
\hline \multirow[t]{2}{*}{ High } & 0.255 & 0.125 & 0.056 & 0.114 & 0.246 & \\
\hline & $\mathrm{GMV}_{\mathrm{B}}$ & Middle $_{\mathrm{B}}$ & $\operatorname{High}_{B}$ & GMV & Middle & High \\
\hline$r_{p}$ & 1.00525 & 1.01187 & 1.01414 & 1.00531 & 1.01581 & 1.01799 \\
\hline$\sigma\left(r_{p}\right)$ & 3.71518 & 5.48174 & 6.60589 & 3.72246 & 6.23546 & 7.04822 \\
\hline Sharpe & 0.113 & 0.197 & 0.198 & 0.115 & 0.237 & 0.240 \\
\hline MAD & 1.189 & 1.069 & 1.199 & 1.376 & 1.123 & 1.263 \\
\hline \multicolumn{7}{|c|}{ Domestic CEF } \\
\hline \multicolumn{7}{|c|}{ Panel C: } \\
\hline \multicolumn{7}{|c|}{$\operatorname{DCER}(\gamma=5)$} \\
\hline GMV & 0.024 & 0.028 & 0.000 & 0.001 & 0.015 & \\
\hline Middle & 0.231 & 0.066 & 0.110 & 0.143 & 0.240 & \\
\hline \multirow[t]{2}{*}{ High } & 0.233 & 0.078 & 0.087 & 0.126 & 0.245 & \\
\hline & $\mathrm{GMV}_{\mathrm{B}}$ & Middle $_{\mathrm{B}}$ & $\operatorname{High}_{B}$ & GMV & Middle & High \\
\hline$r_{p}$ & 1.00939 & 1.01142 & 1.01233 & 1.00971 & 1.01741 & 1.01901 \\
\hline$\sigma\left(r_{p}\right)$ & 4.90411 & 5.59245 & 5.96283 & 4.93168 & 6.77143 & 7.28189 \\
\hline Sharpe & 0.170 & 0.185 & 0.189 & 0.176 & 0.242 & 0.247 \\
\hline MAD & 0.903 & 0.659 & 0.770 & 1.405 & 0.924 & 1.046 \\
\hline
\end{tabular}

The table reports summary statistics of the out-of-sample performance using Michaud optimization in the Low state. The Low state is when the lagged one-month US Treasury Bill return is lower than normal. Two sets of RE portfolios are estimated. The first set uses a benchmark investment universe consisting of the returns of domestic assets of either six size/BM portfolios (panel A), ten industry portfolios (panel B), and three domestic equity CEF portfolios (panel C). The second set is the augmented investment universe, which adds four international equity CEF portfolios to the benchmark investment universe. Three RE portfolios are formed from the benchmark investment universe $\left(\mathrm{GMV}_{\mathrm{B}}, \mathrm{Middle}_{\mathrm{B}}\right.$, and $\mathrm{High}_{\mathrm{B}}$ ) and from the augmented investment universe (GMV, Middle, and High) using a risk tolerance level set equal to 0 (GMV), 0.2 (Middle), and 0.5 (High). The DCER measure (\%) is the change in CER performance between the GMV and $\mathrm{GMV}_{\mathrm{B}}$, Middle and Middle ${ }_{\mathrm{B}}$, and High and $\mathrm{High}_{\mathrm{B}} \mathrm{strategies}$ The summary statistics of performance include the average, standard deviation (SD), the 5\% and $10 \%$ percentiles, and median of the DCER measure. The final rows of each panel include the average out-of-sample mean return $\left(r_{p}\right)$ and volatility $\left(\sigma\left(r_{p}\right)\right)$ of the strategies from the benchmark and augmented investment 
Table 4 (continued)

universes, the corresponding Sharpe performance, and the mean absolute deviation (MAD) of the optimal weights from an equal weighted strategy. The simulation uses the sample moments of the benchmark assets and international CEF portfolios during the Low state in the January 1994 and October 2019 sample period as the true $\mathrm{u}$ and $\mathrm{V}$. The number of simulation trials is 1000 and the risk aversion $(\gamma)$ level for the DCER measure is set equal to 5

universes. The Middle and High portfolios have a significant positive mean DCER measure at the $10 \%$ percentile using the domestic CEF portfolios benchmark universe. ${ }^{10}$ The GMV, Middle, and High portfolios also provide a higher Sharpe performance than the $\mathrm{GMV}_{\mathrm{B}}$, Middle $\mathrm{B}$, and $\mathrm{High}_{\mathrm{B}}$ portfolios. The superior performance of the Middle and High portfolios is driven by a higher mean out-of-sample average return. For the GMV portfolio, the diversification benefits are driven by a higher mean out-of-sample average return and lower volatility for the size/BM and industry portfolio benchmark universes. The superior performance of the GMV portfolio in the High state is driven by both the low volatility and lower correlations of the CEF portfolios. The lower volatility and correlations also have an impact on the superior performance of the Middle and High portfolios as well.

Table 7 shows that the pattern in optimal weights in the High state differs from Table 5. For the GMV portfolio, there is now a significant mean weight on the Asia Pacific CEF portfolio, which drives the diversification benefits of the GMV portfolio. For the Middle and High portfolios, there are significant positive mean weights on the EM and Asia Pacific CEF portfolios. The EM CEF portfolio plays the dominant role here, especially in the High portfolio. This result suggests that different investment sectors drive the diversification benefits in different economic states.

The analysis in Tables 3, 4, 5, 6 and 7 ignores the impact of trading costs. Since CEF stock returns are used, the only cost in forming the portfolios is in buying the individual CEF. Since there are only a small number of CEF in each CEF portfolio, the trading costs are likely to be minor. In contrast, the size/BM portfolios and industry portfolios, ${ }^{11}$ include a much larger number of stocks and so the trading costs are likely to be larger for these sets of benchmark assets. As a result, it is likely that the out-of-sample diversification benefits of the international CEF are likely to be stronger than observed in Tables 4, 5, 6 and 7.

One concern of the results in Tables 4, 5, 6 and 7 is that the lagged one-month US Treasury Bill return has been so low by and large from the global financial crisis of 2007/2008. To examine the impact of this issue, I identify all months within the sample period, where the one-month US Treasury Bill return is less than or equal to $0.03 \% .{ }^{12}$ I then run the tests over this sample period where the sample moments of $\mathrm{u}$ and $\mathrm{V}$ over this period are set equal to the true values $u_{\text {true }}$ and $V_{\text {true }}$, and the number of simulated returns is set equal to the number of months in this period. ${ }^{13}$ I find that using the size/BM portfolios or the industry

\footnotetext{
10 The mean DCER measures for the Middle and High portfolios are significantly positive at the $5 \%$ percentile, when $\gamma=2$ for the domestic CEF benchmark universe.

11 Novy-Marx and Velikov (2016) provide estimates of trading costs of efficient market anomalies.

12 This covers the period November 2008 and December 2016.

13 Results are available on request.
} 
Table 5 Optimal Portfolio Weights: Low State

\begin{tabular}{|c|c|c|c|c|c|c|}
\hline & \multicolumn{2}{|l|}{ GMV } & \multicolumn{2}{|c|}{ Middle } & \multicolumn{2}{|l|}{ High } \\
\hline & Mean & $10 \%$ & Mean & $10 \%$ & Mean & $10 \%$ \\
\hline \multicolumn{7}{|l|}{ Panel A: } \\
\hline \multicolumn{7}{|l|}{ Size/BM } \\
\hline Small/Growth & 0 & 0 & 0.034 & 0 & 0.044 & 0 \\
\hline Small/Neutral & 0.005 & 0 & 0.118 & 0.004 & 0.046 & 0.000 \\
\hline Small/Value & 0.000 & 0 & 0.143 & 0.007 & 0.152 & 0.005 \\
\hline Big/Growth & 0.605 & 0.313 & 0.069 & 0.000 & 0.015 & 0 \\
\hline Big/Neutral & 0.365 & 0.114 & 0.017 & 0 & 0.002 & 0 \\
\hline Big/Value & 0 & 0 & 0.000 & 0 & 0.000 & 0 \\
\hline Global & 0.010 & 0 & 0.176 & 0.012 & 0.192 & 0.009 \\
\hline EM & 0.003 & 0 & 0.087 & 0.001 & 0.087 & 0.001 \\
\hline Asia Pacific & 0.008 & 0 & 0.240 & 0.023 & 0.278 & 0.022 \\
\hline Europe & 0 & 0 & 0.113 & 0.004 & 0.180 & 0.009 \\
\hline \multicolumn{7}{|l|}{ Panel B: } \\
\hline \multicolumn{7}{|l|}{ Industry } \\
\hline NonDur & 0.380 & 0.163 & 0.081 & 0.001 & 0.020 & 0 \\
\hline Durbl & 0.000 & 0 & 0.113 & 0.004 & 0.180 & 0.007 \\
\hline Manuf & 0.000 & 0 & 0.028 & 0 & 0.010 & 0 \\
\hline Enrgy & 0.076 & 0.006 & 0.093 & 0.001 & 0.043 & 0 \\
\hline Hi Tec & 0.000 & 0 & 0.070 & 0.000 & 0.093 & 0.001 \\
\hline Telcm & 0.002 & 0 & 0.012 & 0 & 0.008 & 0 \\
\hline Shops & 0.069 & 0.007 & 0.089 & 0.001 & 0.039 & 0 \\
\hline Hlth & 0.263 & 0.102 & 0.014 & 0 & 0.004 & 0 \\
\hline Utils & 0.199 & 0.059 & 0.013 & 0 & 0.004 & 0 \\
\hline Other & 0.000 & 0 & 0.000 & 0 & 0.000 & 0 \\
\hline Global & 0.003 & 0 & 0.135 & 0.006 & 0.150 & 0.004 \\
\hline EM & 0.000 & 0 & 0.060 & 0.000 & 0.064 & 0.000 \\
\hline Asia Pacific & 0.000 & 0 & 0.194 & 0.017 & 0.235 & 0.017 \\
\hline Europe & 0 & 0 & 0.090 & 0.001 & 0.143 & 0.003 \\
\hline \multicolumn{7}{|l|}{ Panel C: } \\
\hline \multicolumn{7}{|l|}{ Domestic CEF } \\
\hline Small & 0.004 & 0 & 0.095 & 0.001 & 0.075 & 0.000 \\
\hline Mid Cap & 0.749 & 0.554 & 0.157 & 0.007 & 0.052 & 0 \\
\hline Large & 0.216 & 0.050 & 0.043 & 0.000 & 0.013 & 0 \\
\hline Global & 0.007 & 0 & 0.185 & 0.010 & 0.215 & 0.009 \\
\hline EM & 0.004 & 0 & 0.098 & 0.001 & 0.100 & 0.001 \\
\hline Asia Pacific & 0.017 & 0.000 & 0.269 & 0.028 & 0.315 & 0.028 \\
\hline Europe & 0.000 & 0 & 0.150 & 0.005 & 0.226 & 0.010 \\
\hline
\end{tabular}

The table reports summary statistics of the optimal RE portfolio weights using Michaud optimization across the Low economic state. The Low state is when the lagged one-month UK Treasury Bill return is lower than normal. Two sets of RE portfolios are estimated. The first set uses a benchmark investment universe consisting of the returns of domestic assets of either six size/BM portfolios (panel A), ten industry portfolios (panel B), and three domestic equity CEF portfolios (panel C). The second set is the 
Table 5 (continued)

augmented investment universe, which adds four international equity CEF portfolios to the benchmark investment universe. Three RE portfolios are formed from the benchmark investment universe $\left(\mathrm{GMV}_{\mathrm{B}}\right.$, Middle $_{\mathrm{B}}$, and $\mathrm{High}_{\mathrm{B}}$ ) and from the augmented investment universe (GMV, Middle, and High). The summary statistics of optimal weights include the average, and $10 \%$ percentile of the optimal weights for the GMV, Middle, and High portfolios. The simulation uses the sample moments of the benchmark assets and CEF portfolios from the Low economic state between the January 1994 and October 2019 sample period as the true $\mathrm{u}$ and $\mathrm{V}$. The number of simulation trials is 1000

portfolios as the benchmark universe, that the GMV, Middle, and High RE portfolios do not provide out-of-sample diversification benefits. The mean DCER measures are all negative. It is only for the domestic CEF portfolios as the benchmark universe, where only the Middle and High portfolios deliver a significant positive mean DCER measure. The results suggest that on the whole the out-of-sample diversification benefits in the Low state by the international CEF portfolios is not driven by the Treasury Bill return months being close to zero.

The final tests, I consider is whether the diversification benefits across states are robust to using an alternative lagged information variable. I repeat the tests of Tables 4, 5, 6 and 7 but this time use the lagged one-month dividend yield on the S\&P 500 index, which is available on Amit Goyal's web site, as the lagged information variable. The results suggest that the out-of-sample diversification benefits vary across the economic states. There are no benefits when the lag dividend yield is lower than normal and the benefits are strongest in the High state. All of the mean DCER measures are positive and statistically significant at the $10 \%$ level, except for the High portfolio. The High portfolio has the largest mean DCER measure but also a higher volatility in the DCER measure. All three portfolios provide a higher out-of-sample Sharpe performance relative to the $\mathrm{GMV}_{\mathrm{B}}$, Middle $_{\mathrm{B}}$, and $\mathrm{High}_{\mathrm{B}}$ portfolios. Although the diversification benefits are weaker when using the lag dividend yield to identify the states, the positive benefits in the High state are consistent with diversification benefits in the Low state using the lag Treasury Bill returns, given the positive predictive ability of the lag dividend yield of financial asset returns (Ferson and Qian 2004).

\section{Conclusion}

My study examines the out-of-sample diversification benefits of US international equity CEF in the presence of market frictions. There are three main findings in my study. First, the international CEF do not provide out-of-sample diversification benefits across the whole sample period. This finding is robust across all benchmark investment universes. All of the mean DCER measures are small and negative and 
Table 6 Out-of-sample performance: high state

\begin{tabular}{|c|c|c|c|c|c|c|}
\hline & Mean & SD & $5 \%$ & $10 \%$ & Median & \\
\hline \multicolumn{7}{|c|}{ Panel A: } \\
\hline \multicolumn{7}{|c|}{ Size/BM } \\
\hline \multicolumn{7}{|c|}{$\operatorname{DCER}(\chi=5)$} \\
\hline GMV & 0.062 & 0.021 & 0.024 & 0.031 & 0.064 & \\
\hline Middle & 0.176 & 0.077 & 0.041 & 0.065 & 0.184 & \\
\hline \multirow[t]{2}{*}{ High } & 0.199 & 0.101 & 0.038 & 0.075 & 0.205 & \\
\hline & $\mathrm{GMV}_{\mathrm{B}}$ & Middle $_{\mathrm{B}}$ & $\operatorname{High}_{B}$ & GMV & Middle & High \\
\hline$r_{p}$ & 1.01095 & 1.01187 & 1.01186 & 1.01146 & 1.01458 & 1.01526 \\
\hline$\sigma\left(r_{p}\right)$ & 3.11275 & 3.61361 & 3.75459 & 3.03718 & 4.07187 & 4.40672 \\
\hline Sharpe & 0.270 & 0.258 & 0.248 & 0.294 & 0.296 & 0.289 \\
\hline MAD & 1.289 & 0.972 & 0.967 & 1.391 & 1.168 & 1.249 \\
\hline \multicolumn{7}{|c|}{ Panel B: } \\
\hline \multicolumn{7}{|c|}{ Industry } \\
\hline \multicolumn{7}{|c|}{$\operatorname{DCER}(\gamma=5)$} \\
\hline GMV & 0.067 & 0.024 & 0.029 & 0.038 & 0.066 & \\
\hline Middle & 0.127 & 0.072 & 0.018 & 0.043 & 0.123 & \\
\hline \multirow[t]{2}{*}{ High } & 0.144 & 0.103 & 0.013 & 0.039 & 0.133 & \\
\hline & $\mathrm{GMV}_{\mathrm{B}}$ & Middle $_{\text {B }}$ & $\operatorname{High}_{B}$ & GMV & Middle & High \\
\hline$r_{p}$ & 1.01121 & 1.01247 & 1.01227 & 1.01177 & 1.01435 & 1.01476 \\
\hline$\sigma\left(r_{p}\right)$ & 2.35583 & 2.90925 & 3.09084 & 2.25092 & 3.25222 & 3.64669 \\
\hline Sharpe & 0.369 & 0.341 & 0.315 & 0.411 & 0.363 & 0.335 \\
\hline MAD & 0.997 & 1.139 & 1.156 & 1.169 & 1.263 & 1.314 \\
\hline \multicolumn{7}{|c|}{ Panel C: } \\
\hline \multicolumn{7}{|c|}{ Domestic CEF } \\
\hline \multicolumn{7}{|c|}{$\operatorname{DCER}(\gamma=5)$} \\
\hline GMV & 0.017 & 0.015 & -0.005 & 0.000 & 0.017 & \\
\hline Middle & 0.105 & 0.066 & -0.005 & 0.022 & 0.114 & \\
\hline \multirow[t]{2}{*}{ High } & 0.113 & 0.080 & -0.018 & 0.017 & 0.117 & \\
\hline & $\mathrm{GMV}_{\mathrm{B}}$ & Middle $_{B}$ & $\operatorname{High}_{B}$ & GMV & Middle & High \\
\hline$r_{p}$ & 1.01226 & 1.01301 & 1.01308 & 1.01245 & 1.01530 & 1.015941 \\
\hline$\sigma\left(r_{p}\right)$ & 3.49350 & 3.84464 & 3.94702 & 3.50266 & 4.42332 & 4.717381 \\
\hline Sharpe & 0.278 & 0.272 & 0.267 & 0.283 & 0.288 & 0.284 \\
\hline MAD & 1.229 & 0.776 & 0.783 & 1.379 & 1.066 & 1.161 \\
\hline
\end{tabular}

The table reports summary statistics of the out-of-sample performance using Michaud optimization in the High state. The High state is when the lagged one-month US Treasury Bill return is higher than normal. Two sets of RE portfolios are estimated. The first set uses a benchmark investment universe consisting of the returns of domestic assets of either six size/BM portfolios (panel A), ten industry portfolios (panel B), and three domestic equity CEF portfolios (panel C). The second set is the augmented investment universe, which adds four international equity CEF portfolios to the benchmark investment universe. Three RE portfolios are formed from the benchmark investment universe $\left(\mathrm{GMV}_{\mathrm{B}}, \mathrm{Middle}_{\mathrm{B}}\right.$, and $\mathrm{High}_{\mathrm{B}}$ ) and from the augmented investment universe (GMV, Middle, and High) using a risk tolerance level set equal to 0 (GMV), 0.2 (Middle), and 0.5 (High). The DCER measure (\%) is the change in CER performance between the GMV and $\mathrm{GMV}_{\mathrm{B}}$, Middle and Middle $\mathrm{B}_{\mathrm{B}}$, and High and $\mathrm{High}_{\mathrm{B}} \mathrm{strategies}$ The summary statistics of performance include the average, standard deviation (SD), the 5\% and $10 \%$ percentiles, and median of the DCER measure. The final rows of each panel include the average out-of-sample mean return $\left(r_{p}\right)$ and volatility $\left(\sigma\left(r_{p}\right)\right)$ of the strategies from the benchmark and augmented investment 
Table 6 (continued)

universes, and the corresponding Sharpe performance, and the mean absolute deviation (MAD) of the optimal weights from an equal weighted strategy. The simulation uses the sample moments of the benchmark assets and international CEF portfolios during the High state in the January 1994 and October 2019 sample period as the true $\mathrm{u}$ and $\mathrm{V}$. The number of simulation trials is 1000 and the risk aversion $(\gamma)$ level for the DCER measure is set equal to 5

the GMV, Middle, and High portfolios fail to provide a higher Sharpe performance than the corresponding $\mathrm{GMV}_{\mathrm{B}}$, Middle $_{\mathrm{B}}$, and $\mathrm{High}_{\mathrm{B}}$ portfolios. The optimal portfolio weights in the GMV, Middle, and High portfolios are concentrated in the benchmark assets.

Second, the out-of-sample diversification benefits of international CEF varies across economic states. The international CEF do not provide any diversification benefits in the Normal state. However, in the Low and High states, the international CEF do provide significant out-of-sample diversification benefits. In the Low state, the benefits only exist for the Middle and High portfolios, where the Middle and High portfolios significantly outperform the Middle ${ }_{B}$ and $\mathrm{High}_{\mathrm{B}}$ portfolios using the DCER measure. This finding is robust across the different benchmark investment universes. In the High state, the GMV portfolio also provides significant out-ofsample diversification benefits when the benchmark investment universe is either the size/BM portfolios or the industry portfolios.

Third, I find that different investment sectors of international CEF drive the outof-sample diversification benefits between the Low and High states. In the Low state, all four international CEF portfolios play a role in the diversification benefits. The largest mean weight in the Middle and High portfolios is in the Asia Pacific CEF portfolio and a lesser role played by the Global and Europe CEF portfolios. In the High state, the Asia Pacific CEF portfolio drives the diversification benefits for the GMV portfolio but the EM CEF portfolio drives the diversification benefits in the Middle and High portfolios, with a lesser role played by Asia Pacific CEF portfolio.

My study provides support that US international equity CEF do deliver out-ofsample diversification benefits when the lagged one-month US Treasury Bill return is lower or higher than normal. This provides some support that international CEF can be a useful vehicle for institutional investors for investing in markets (or areas of markets) where they are not normally exposed (Parwada and Siaw 2014). The important point from this study is that relevant economic state is an important issue as to whether the international CEF are able to deliver diversification benefits. My study has focused on international equity CEF. It would be of interest to consider the diversification benefits of different managed funds such as Exchange-Traded Funds (ETF) or hedge funds. My study has used the one-month Treasury Bill return and the market dividend yield for conditioning information. It would be of interest to consider alternative lagged information variables such as combination forecasts (Rapach et al. 2010) or investor sentiment (Huang et al. 2015). I leave these issues to future research. 
Table 7 Optimal portfolio weights: high state

\begin{tabular}{|c|c|c|c|c|c|c|}
\hline & \multicolumn{2}{|l|}{ GMV } & \multicolumn{2}{|c|}{ Middle } & \multicolumn{2}{|l|}{ High } \\
\hline & Mean & $10 \%$ & Mean & $10 \%$ & Mean & $10 \%$ \\
\hline \multicolumn{7}{|l|}{ Panel A: } \\
\hline \multicolumn{7}{|l|}{ Size/BM } \\
\hline Small/Growth & 0 & 0 & 0.005 & 0 & 0.013 & 0 \\
\hline Small/Neutral & 0.003 & 0 & 0.051 & 0.000 & 0.045 & 0.000 \\
\hline Small/Value & 0.009 & 0 & 0.054 & 0.000 & 0.054 & 0.000 \\
\hline Big/Growth & 0.130 & 0.020 & 0.065 & 0.000 & 0.040 & 0 \\
\hline Big/Neutral & 0.693 & 0.567 & 0.071 & 0.000 & 0.030 & 0 \\
\hline Big/Value & 0.011 & 0 & 0.251 & 0.027 & 0.204 & 0.010 \\
\hline Global & 0.001 & 0 & 0.010 & 0 & 0.010 & 0 \\
\hline EM & 0.006 & 0 & 0.345 & 0.063 & 0.449 & 0.090 \\
\hline Asia Pacific & 0.138 & 0.058 & 0.128 & 0.004 & 0.136 & 0.003 \\
\hline Europe & 0.004 & 0 & 0.015 & 0 & 0.014 & 0 \\
\hline \multicolumn{7}{|l|}{ Panel B: } \\
\hline \multicolumn{7}{|l|}{ Industry } \\
\hline NonDur & 0.220 & 0.099 & 0.030 & 0 & 0.018 & 0 \\
\hline Durbl & 0.013 & 0.000 & 0.014 & 0 & 0.016 & 0 \\
\hline Manuf & 0.005 & 0 & 0.080 & 0.002 & 0.062 & 0.000 \\
\hline Enrgy & 0.001 & 0 & 0.012 & 0 & 0.016 & 0 \\
\hline Hi Tec & 0.007 & 0.000 & 0.029 & 0.000 & 0.044 & 0 \\
\hline Telcm & 0.125 & 0.044 & 0.019 & 0 & 0.014 & 0 \\
\hline Shops & 0.076 & 0.010 & 0.026 & 0 & 0.018 & 0 \\
\hline Hlth & 0.046 & 0.004 & 0.126 & 0.004 & 0.116 & 0.002 \\
\hline Utils & 0.352 & 0.265 & 0.281 & 0.041 & 0.224 & 0.015 \\
\hline Other & 0.019 & 0.000 & 0.012 & 0 & 0.009 & 0 \\
\hline Global & 0.000 & 0 & 0.003 & 0 & 0.003 & 0 \\
\hline EM & 0.003 & 0 & 0.267 & 0.041 & 0.353 & 0.054 \\
\hline Asia Pacific & 0.124 & 0.065 & 0.087 & 0.002 & 0.095 & 0.001 \\
\hline Europe & 0.001 & 0 & 0.007 & & 0.007 & 0 \\
\hline \multicolumn{7}{|l|}{ Panel C: } \\
\hline \multicolumn{7}{|l|}{ Domestic CEF } \\
\hline Small & 0.009 & 0 & 0.056 & 0.000 & 0.060 & 0 \\
\hline Mid Cap & 0.043 & 0.001 & 0.259 & 0.029 & 0.208 & 0.011 \\
\hline Large & 0.819 & 0.682 & 0.127 & 0.004 & 0.056 & 0.000 \\
\hline Global & 0.009 & 0 & 0.009 & 0 & 0.007 & 0 \\
\hline EM & 0.010 & 0 & 0.392 & 0.090 & 0.504 & 0.142 \\
\hline Asia Pacific & 0.088 & 0.019 & 0.135 & 0.003 & 0.145 & 0.002 \\
\hline Europe & 0.018 & 0.000 & 0.018 & 0 & 0.016 & 0 \\
\hline
\end{tabular}

The table reports summary statistics of the optimal RE portfolio weights using Michaud optimization across the High economic state. The High state is when the lagged one-month UK Treasury Bill return is higher than normal. Two sets of RE portfolios are estimated. The first set uses a benchmark investment universe consisting of the returns of domestic assets of either six size/BM portfolios (panel A), ten industry portfolios (panel B), and three domestic equity CEF portfolios (panel C). The second set is the 
Table 7 (continued)

augmented investment universe, which adds four international equity CEF portfolios to the benchmark investment universe. Three RE portfolios are formed from the benchmark investment universe $\left(\mathrm{GMV}_{\mathrm{B}}\right.$, Middle $_{\mathrm{B}}$, and $\mathrm{High}_{\mathrm{B}}$ ) and from the augmented investment universe (GMV, Middle, and High). The summary statistics of optimal weights include the average, and $10 \%$ percentile of the optimal weights for the GMV, Middle, and High portfolios. The simulation uses the sample moments of the benchmark assets and CEF portfolios from the High economic state between the January 1994 and October 2019 sample period as the true $\mathrm{u}$ and $\mathrm{V}$. The number of simulation trials is 1000

Acknowledgements I am grateful for permission to use the resampled portfolio efficiency by Richard Michaud. I am grateful for the use of data from Ken French's Data Library and Amit Goyal. I am grateful for the comments from three anonymous reviewers.

Open Access This article is licensed under a Creative Commons Attribution 4.0 International License, which permits use, sharing, adaptation, distribution and reproduction in any medium or format, as long as you give appropriate credit to the original author(s) and the source, provide a link to the Creative Commons licence, and indicate if changes were made. The images or other third party material in this article are included in the article's Creative Commons licence, unless indicated otherwise in a credit line to the material. If material is not included in the article's Creative Commons licence and your intended use is not permitted by statutory regulation or exceeds the permitted use, you will need to obtain permission directly from the copyright holder. To view a copy of this licence, visit http://creativecommons.org/licen ses/by/4.0/.

\section{References}

Bekaert, G., Urias, M.S.: Diversification, integration and emerging market closed-end funds. J. Financ. 51, 835-869 (1996)

Bekaert, G., Urias, M.S.: Is there a free lunch in emerging markets equities? J. Portf. Manag. 25, 83-95 (1999)

Berk, J.B., Stanton, R.: Managerial ability, compensation, and the closed-end fund discount. J. Financ. 62, 529-556 (2007)

Best, M.J., Grauer, R.R.: The efficient set mathematics when mean-variance problems are subject to general linear constraints. J. Econ. Bus. 42, 105-120 (1990)

Best, M.J., Grauer, R.R.: On the sensitivity analysis of mean-variance efficient portfolios to changes in the means: some analytical and computational results. Rev. Financ. Stud. 4, 315-342 (1991)

Cao, J., Fu, R., Jin, Y.: International diversification through iShares and their rivals. J. Risk 19, 25-55 (2017)

Carhart, M.M., Carpenter, J.N., Lynch, A.W., Musto, D.K.: Mutual fund survivorship. Rev. Financ. Stud. 15, 1439-1463 (2002)

Cherkes, M., Sagi, J., Stanton, R.: A liquidity-based theory of closed-end funds. Rev. Financ. Stud. 22, 257-297 (2009)

Chretien, S., Kammoun, M.: Mutual fund performance evaluation and best clienteles. J. Financ. Quant. Anal. 52, 1577-1604 (2017)

Dimson, E., Marsh, P.R., Staunton, M.: Cycling for the good of your wealth, Credit Suisse Global Investment Returns Yearbook (2016)

Edelen, R.M.: Investor flows and the assessed performance of open-end mutual funds. J. Financ. Econ. 53, 439-466 (1999)

Elton, E.J., Gruber, M.J., Blake, C.R., Shacher, O.: Why do closed-end bond funds exist? An additional explanation for the growth in domestic closed-end bond funds. J. Financ. Quant. Anal. 48, 405-425 (2013)

Errunza, V., Hogan, K., Hung, M.W.: Can the gains from international diversification be achieved without trading abroad? J. Financ. 54, 2075-2107 (1999) 
Fama, E.F., French, K.R.: Common risk factors in the returns on stocks and bonds. J. Financ. Econ. 33, 3-56 (1993)

Fama, E.F., Jensen, M.C.: Agency problems and residual claims. J. Law Econ. 26, 327-349 (1983)

Fama, E.F., Schwert, G.W.: Asset returns and inflation. J. Financ. Econ. 5, 115-146 (1977)

Ferson, W.E.: Changes in expected security returns, risk and the level of interest rates. J. Financ. 44, 1191-1217 (1989)

Ferson, W.E., Henry, T., Kisgen, D.: Evaluating government bond fund performance with stochastic discount factors. Rev. Financ. Stud. 19, 423-456 (2006a)

Ferson, W.E., Kisgen, D., Henry, T.: Fixed income fund performance across economic states. Res. Financ. 23, 1-62 (2006b)

Ferson, W.E., Qian, M.: Conditional performance evaluation revisited, Research Foundation Monograph. CFA Institute, Charlottesville (2004)

Ferson, W.E., Sarkissian, S., Simin, T.: Spurious regressions in financial economics. J. Financ. 58, 1393-1414 (2003)

Ferson, W.E., Schadt, R.W.: Measuring fund strategy and performance in changing economic conditions. J. Financ. 51, 425-462 (1996)

Fletcher, J.: An empirical examination of the diversification benefits of U.K. international equity closed-end funds. Int. Rev. Financ. Anal. 55, 23-34 (2018)

Giannetti, M., Kahraman, B.: Open-end organizational structures and limits to arbitrage. Rev. Financ. Stud. 31, 773-810 (2018)

Grubel, H.: Internationally diversified portfolios: Welfare gains and capital flows. Am. Econ. Rev. 58, 1299-1314 (1968)

Hodrick, R.J., Zhang, X.: International diversification revisited. Working Paper. University of Columbia (2014)

Huang, D., Jiang, F., Tu, J., Zhou, G.: Investor sentiment aligned: a powerful predictor of stock returns. Rev. Financ. Stud. 28, 791-837 (2015)

Jarrow, R., Protter, P.: A rational asset pricing model for premiums and discounts on closed-end funds: the bubble theory. Math. Financ. 29, 1157-1170 (2019)

Jobson, J.D., Korkie, R.M.: Putting Markowitz theory to work. J. Portf. Manag. 7, 70-74 (1981)

Kan, R., Wang, X., Zhou, G.: Optimal portfolio choice with estimation risk: The risk-free asset case, Working Paper, University of Toronto (2021)

Kan, R., Zhou, G.: Optimal portfolio choice with parameter uncertainty. J. Financ. Quant. Anal. 42, 621-656 (2007)

Ledoit, O., Wolf, M.: Nonlinear shrinkage of the covariance matrix for portfolio selection: Markowitz meets Goldilocks. Rev. Financ. Stud. 30, 4349-4388 (2017)

Lessard, D.: World, national and industry factors in equity returns. J. Finan. 29, 379-391 (1973)

Li, K., Sarkar, A., Wang, Z.: Diversification benefits of emerging markets subject to portfolio constraints. J. Empirical Financ. 10, 57-80 (2003)

Liu, E.X.: Portfolio diversification and international corporate bonds. J. Financ. Quant. Anal. 51, 959-983 (2016)

Markowitz, H.: Portfolio selection. J. Financ. 7, 77-91 (1952)

Markowitz, H., Usmen, N.: Resampled frontiers versus diffuse bayes: an expirment. J. Inves. Manag. 1, 9-25 (2003)

Michaud, R.O.: The Markowitz optimization enigma: is 'optimized' optimal. Financ. Anal. J. 45, 31-42 (1989)

Michaud, R.O., Esch, D.N.: When Michaud optimization fails, Working Paper, New Frontier Advisors (2018)

Michaud, R.O., Esch, D.N., Michaud, R.: Estimation error and the fundamental law of active management: is quant fundamentally flawed? J. Invest. 29, 20-30 (2020)

Michaud, R.O., Michaud, R.: Efficient asset management: a practical guide to stock portfolio optimization and asset allocation, 2nd edn. Oxford University Press, Oxford (2008)

Novy-Marx, R., Velikov, M.: A taxonomy of anomalies and their trading costs. Rev. Financ. Stud. 29, 104-147 (2016)

Parwada, J., Siaw, K.K.: Empirical test of the liquidity-based theory of closed-end funds, Working Paper, University of New South Wales (2014)

Perez-Quiros, G., Timmermann, A.: Firm size and cyclical variations in stock returns. J. Financ. 55, 1229-1262 (2000) 
Rapach, D., Strauss, J.K., Zhou, G.: Out-of-sample equity prediction: combination forecasts and links to the real economy. Rev. Financ. Stud. 23, 821-862 (2010)

Sharpe, W.F.: Mutual fund performance. J. Bus. 39, 119-138 (1966)

Solnik, B.H.: Why not diversify internationally rather than domestically? Financ. Anal. J. 30, 48-54 (1974)

Tu, J., Zhou, G.: Markowitz meets Talmud: a combination of sophisticated and naïve diversification strategies. J. Financ. Econ. 99, 204-215 (2011)

Publisher's Note Springer Nature remains neutral with regard to jurisdictional claims in published maps and institutional affiliations.

Professor Jonathan Fletcher is a Professor of Finance at the University of Strathclyde in Glasgow, Scotland. His research and teaching interests lie in the areas of portfolio optimization, asset pricing, and evaluating fund performance. He has published a number of articles in the Financial Analysts Journal, Journal of Banking and Finance, Journal of Empirical Finance, Journal of Business Finance and Accounting, Journal of Financial Research, Financial Review, Journal of Financial Services Research, and European Journal of Finance among others. 